\title{
Psychiatric comorbidity in individuals with bullous pemphigoid and all bullous disorders in the Danish national registers
}

\author{
Marianna Rania ${ }^{1,2,3}$, Liselotte Vogdrup Petersen ${ }^{4,5}$, Michael Eriksen Benros ${ }^{6}$, Zhi Liu, Luis Diaz ${ }^{7}$ and \\ Cynthia M. Bulik ${ }^{3,8,9^{*}}$ (i)
}

\begin{abstract}
Background: Bullous pemphigoid (BP) is an autoimmune blistering skin disease that takes a profound physical and mental toll on those affected. The aim of the study was to investigate the bidirectional association between BP and all bullous disorders (ABD) with a broad array of psychiatric disorders, exploring the influence of prescribed medications.

Methods: This nationwide, register-based cohort study encompassed 6,470,450 individuals born in Denmark and alive from 1994 to 2016. The hazard ratios (HRs) of a subsequent psychiatric disorder in patients with BP/ABD and the reverse exposure and outcome were evaluated.

Results: Several psychiatric disorders were associated with increased risk of subsequent BP (4.18-fold for intellectual disorders, 2.32-fold for substance use disorders, 2.01-fold for schizophrenia and personality disorders, 1.92-1.85-1.49-fold increased risk for organic disorders, neurotic and mood disorders), independent of psychiatric medications. The association between BP and subsequent psychiatric disorders was not significant after adjusting for BP medications, except for organic disorders (HR 1.27, Cl 1.04-1.54). Similar results emerged with ABD.

Conclusion: Psychiatric disorders increase the risk of a subsequent diagnosis of BP/ABD independent of medications, whereas medications used for the treatment of BP/ABD appear to account for the subsequent onset of psychiatric disorders. Clinically, an integrated approach attending to both dermatological and psychiatric symptoms is recommended, and dermatologists should remain vigilant for early symptoms of psychiatric disorders to decrease mental health comorbidity.
\end{abstract}

Keywords: Bullous pemphigoid, Bullous disorders, Mental health, Psychiatric disorders, Comorbidity

\section{Background}

Bullous pemphigoid (BP) is categorized among a heterogeneous panel of bullous disorders (ABD), and is characterized clinically by itchy and tense serous or hemorrhagic sub-epidermal blisters that can be localized

\footnotetext{
* Correspondence: cynthia_bulik@med.unc.edu

${ }^{3}$ Department of Medical Epidemiology and Biostatistics, Karolinska Institutet, Stockholm, Sweden

${ }^{8}$ Department of Psychiatry, University of North Carolina at Chapel Hill, Chapel Hill, NC, USA

Full list of author information is available at the end of the article
}

or widespread on the trunk and extremities and typically affects older individuals $[1,2]$.

The incidence of BP in Europe is estimated to be 2.542.8 cases/million/year [3-9], with incidence increasing over the past eight decades [10] and a nearly 300-fold increase in those over age 90 compared to those younger than 60 [4]. This rise may reflect increasing average life expectancy, increasing use of polypharmacy, and improved detection and diagnosis [5]. BP is associated with considerable functional impairment and distress [11, 12] and the one-year mortality rate of BP in Europe is

(c) The Author(s). 2020, corrected publication 2020. Open Access This article is licensed under a Creative Commons Attribution 4.0 International License, which permits use, sharing, adaptation, distribution and reproduction in any medium or format, as long as you give appropriate credit to the original author(s) and the source, provide a link to the Creative Commons licence, and indicate if changes were made. The images or other third party material in this article are included in the article's Creative Commons licence, unless indicated otherwise in a credit line to the material. If material is not included in the article's Creative Commons licence and your intended use is not permitted by statutory regulation or exceeds the permitted use, you will need to obtain permission directly from the copyright holder. To view a copy of this licence, visit http://creativecommons.org/ licenses/by/4.0/. The Creative Commons Public Domain Dedication waiver (http://creativecommons.org/publicdomain/zero/1. 0/) applies to the data made available in this article, unless otherwise stated in a credit line to the data. 
26.7\%, although other factors should be considered (high somatic comorbidity and polypharmacy) [13].

BP is an organ-specific autoimmune disease mediated by IgG autoantibodies that target two epidermal hemidesmosomal antigens crucial for adhesion between epidermis and dermis, BP230 (or BP Ag1/dystonin-e) [14], and BP180 (or BP Ag2/collagen XVII) [15, 16]. These autoantibodies induce sub-epidermal blisters in the skin by triggering an inflammatory response mediated by complement activation, mast cells, eosinophils, and neutrophils $[2,17]$.

BP antigens have been identified in brain and neuronal tissue $[18,19]$ and high levels of autoantibodies against BP antigens have been found in individuals affected by other neurological disorders [20-22]. Significant associations have been reported between BP and neurological diseases [23, 24] and even if mechanisms underlying this association are unclear, brain-reactive antibodies have been detected in the sera of individuals with BP, which might account for the association [22, 25].

To date, only few studies have explored psychiatric comorbidity in individuals with BP, and significantly elevated odds ratios (OR) have been reported for schizophrenia (OR range 1.25-2.7) [26-28], major depressive disorder, and bipolar disorder (OR range 1.19-5.25) [28, 29], although these observations have not been universally replicated [30].

Försti et al. [27] conducted a large nationwide retrospective study on the association between $\mathrm{BP}$ and neurological and psychiatric disorders. BP patients were at increased risk for schizotypal and delusional disorders, schizophrenia, bipolar affective disorder, major depressive disorder, neurotic, stress related and somatoform disorders, and personality disorders (ORs 1.27-2.7), with higher risk of BP after receiving a psychiatric diagnosis than vice-versa. However, this study was restricted to psychiatric diagnoses recorded in specialized settings and included patients with basal cell carcinoma as control group.

Importantly, medications used to treat BP, primarily corticosteroids, have been associated with the onset of psychiatric disorders [31, 32] and some antipsychotic, antidepressant, and anxiolytic medications may increase risk for BP/ABD [29, 33-36]. Many questions remain regarding the association between $\mathrm{BP} / \mathrm{ABD}$ and psychiatric disorders that can best be addressed by population health registers with universal diagnostic detection and prescription records.

In order to fully address the nature of the relation between $\mathrm{BP} / \mathrm{ABD}$ and psychiatric disorders, we conducted a comprehensive register-based investigation of lifetime co-occurrence of BP/ABD and a broad array of psychiatric illnesses using the Danish nationwide registers to explore the nature and direction of the association, and the extent to which medications prescribed to treat each class of illness influences any observed relation.

\section{Methods \\ Study design}

We examined the association between $\mathrm{BP} / \mathrm{ABD}$ and psychiatric disorders. To address temporality, we first estimated the risk for individuals with each psychiatric disorder to receive a later diagnosis of $\mathrm{BP} / \mathrm{ABD}$. We then reversed the question and determined the risk of developing any psychiatric disorder after a diagnosis of $\mathrm{BP} /$ $\mathrm{ABD}$. Individuals with a diagnosis of $\mathrm{BP}, \mathrm{ABD}$, or psychiatric disorder, either existing at the beginning or incident during the observational period, were considered exposed, compared to the general population. As outcomes, only incident cases of $\mathrm{BP}, \mathrm{ABD}$, or psychiatric disorders during the follow-up were considered as subsequent disorders, accordingly, each analysis had different number of individuals at risk at baseline. Observations commenced on January 1, 1994 and stopped with the outcome, emigration, death or end of study period, on December 31st 2016, whichever came first.

\section{Study population and assessment}

Since 1968, the Danish Civil Registration System [37] includes information on each resident in Denmark regarding place and date of birth, sex, and vital status and assigns all Danish residents a unique personal identification number enabling linkage to the national registers of somatic and psychiatric disorders.

Cases of BP/ABD were identified via the Danish National Patient Register [38], which includes all diagnoses entered in Danish general hospitals since 1977, and all outpatient contacts since January 1, 1995. According to the International Statistical Classification of Diseases and Related Health Problems, 10th Revision (ICD-10), L12.0, L12.8-12.9 diagnostic codes were considered BP cases, and L10-L14 were considered ABD cases.

Psychiatric diagnoses were obtained from the Danish Psychiatric Central Research Register [39], which includes all hospitalizations in psychiatric hospitals since 1969 and outpatient treatment and emergency room contacts since 1995. We considered all diagnoses included in the F subchapter of ICD-10 (Mental and behavioral disorders; F00-98). We use abbreviations to refer to psychiatric disorders, in accordance with PlanaRipoll et al. [40]

Prescription medication data were obtained through the National Prescription Registry [41], which contains information on all redeemed prescriptions since January 1, 1995. Medications typically prescribed for the treatment of BP and ABD (H02, systemic corticosteroids; J01A, tetracyclines; L04AX01, azathioprine; L04AX03, methotrexate; L01AA01, cyclophosphamide; L04AD01, 
cyclosporine; L04AA06, mycophenolate mofetil), psychiatric disorders (N05A-B-C, psycholeptics; N06A, antidepressants; N03A, mood stabilizers/antiepileptics), and medications known to be associated with drug-induced $\mathrm{BP}$ (specifically diuretics; C03CA01, furosemide; C03CB01, furosemide and potassium; C03ЕB01, furosemide and potassium-sparing agents; C03DA01, spironolactone) were obtained using Anatomical Therapeutic Chemical (ATC) codes [42]. All personal data from the registers is anonymized when used for research purposes, and the study was approved by the Danish Data Protection Agency and Statistics Denmark, necessitating no informed consent.

\section{Statistical analysis}

We estimated the hazard of developing a psychiatric disorder in patients with $\mathrm{BP} / \mathrm{ABD}$ compared to the general population, by including $\mathrm{BP} / \mathrm{ABD}$ as time dependent variable, and then reversed exposure and outcome, by including each psychiatric disorder as a time dependent variable.

For both sets of analyses, estimates were obtained via Cox regression with the underlying hazard as function age allowed to differ by sex. We present results as hazard ratios (HR) with 95\%-confidence intervals $(95 \% \mathrm{CI})$. Analyses were adjusted for birth decade and calendar year (19941999, 2000-2004, 2005-2009, and 2010-2016) as time dependent variables. Adjustment for medication was handled as a time dependent variable on the day a second prescription for the drug of interest was redeemed.

Analyses were conducted between January and October 2019 and were performed with Stata version 15 [43].

\section{Results}

A total of 6,470,450 individuals were followed from 1994 to 2016. Overall, 1,249,903 individuals died, 117,690 emigrated from Denmark, and 1851 disappeared during the observation period.

Table 1 shows characteristics of the study population.

\section{The association between BP and psychiatric disorders}

The most common psychiatric comorbidities were organic disorders, mood disorders, and neurotic disorders. Among individuals with BP $(N=2892)$, the mean latency until later psychiatric disorders was 4.8 years, and the risk was significantly elevated for the overall category of psychiatric disorders (HR 1.37, CI 1.151.63), and specifically for organic disorder (HR 1.35, CI 1.10-1.64), and mood disorder (HR 1.55, CI 1.12-2.15), compared to individuals without BP. When adjusting for $\mathrm{BP}$ medications and diuretics, only the association between BP and organic disorders (HR 1.27, 1.04-1.54) remained significant.

Among individuals with psychiatric disorders, the risk of subsequent BP was increased by $79 \%$ (HR 1.79 , CI 1.61-1.99; mean latency of 14.6 years), and significantly higher for individuals with prior intellectual disorders (4.18-fold increased risk), substance use disorders (2.32-fold increased risk), schizophrenia (2.01fold increased risk), personality disorders (2.01-fold increased risk), organic (1.92-fold increased risk), neurotic (1.85-fold increased risk), and mood disorders (1.49-fold increased risk), compared with controls. The associations remained significant after adjusting for psychiatric medications and diuretics,

Table 1 Characteristics of the sample

\begin{tabular}{|c|c|c|c|c|}
\hline \multicolumn{5}{|l|}{ Bullous pemphigoid (BP) } \\
\hline & $\begin{array}{l}\mathrm{BP} \text { and no psychiatric } \\
\text { diagnosis }\end{array}$ & Psychiatric diagnosis after BP & $\begin{array}{l}\text { Psychiatric diagnosis } \\
\text { and no BP }\end{array}$ & $\begin{array}{l}\text { BP diagnosis after } \\
\text { psychiatric disorder }\end{array}$ \\
\hline$N^{a}$ & 2370 & 122 & 506,354 & 400 \\
\hline Onset of BP mean (SD) & $77.0(13.4)$ & $76.9(12.4)$ & - & $75.6(12.5)$ \\
\hline Birth year mean (SD) & $1929(15)$ & $1927(13)$ & $1965(27)$ & $1931(14)$ \\
\hline Percentage women (\%) & 53.9 & 56.6 & 54.2 & 64.5 \\
\hline Onset psychiatric disorder mean (SD) & - & $80.3(12.0)$ & $40.1(23.7)$ & $60.1(18.9)$ \\
\hline \multicolumn{5}{|l|}{ All bullous disorders (ABD) } \\
\hline & $\begin{array}{l}\mathrm{ABD} \text { and no psychiatric } \\
\text { diagnosis }\end{array}$ & ABD before psychiatric diagnosis & $\begin{array}{l}\text { Psychiatric diagnosis } \\
\text { and no } A B D\end{array}$ & $\begin{array}{l}\text { Psychiatric diagnosis } \\
\text { before } A B D\end{array}$ \\
\hline$N^{a}$ & 4650 & 236 & 506,028 & 694 \\
\hline Onset of BD mean (SD) & $66.2(22.7)$ & $62.9(27.6)$ & - & $69.5(16.9)$ \\
\hline Birth year mean (SD) & $1941(24)$ & $1940(27)$ & $1965(27)$ & $1938(19)$ \\
\hline Percentage women (\%) & 52.7 & 57.2 & 54.2 & 63.1 \\
\hline Onset psychiatric disorders mean (SD) & - & $67.6(25.3)$ & $40.6(25.8)$ & $54.0(20.9)$ \\
\hline
\end{tabular}

${ }^{a}$ Note survival bias. In the population with neither BP/ABD nor any psychiatric diagnoses including more than 5,767,468/5,764,277 million people, birth year (SD): 1967 (29) and 49.6\% women 
Table 2 Results for bullous pemphigoid (BP) and psychiatric disorders

\begin{tabular}{|c|c|c|c|c|c|}
\hline \multicolumn{6}{|c|}{$\mathrm{BP}$ and subsequent psychiatric disorders ${ }^{a}$} \\
\hline & Psychiatric diagnosis (N) & HR of psychiatric disorder & $\mathrm{Cl}$ & HR of psychiatric disorder ${ }^{c}$ & $\mathrm{Cl}$ \\
\hline Any psychiatric disorder & 122 & 1.37 & $1.15-1.63$ & 1.17 & $0.98-1.40$ \\
\hline Organic disorders (F0) & 99 & 1.35 & $1.10-1.64$ & 1.27 & $1.04-1.54$ \\
\hline Substance use disorders (F1) & 8 & 1.91 & $0.96-3.82$ & 1.55 & $0.78-3.11$ \\
\hline Schizophrenia (F2) & 7 & 1.40 & $0.67-2.94$ & 1.34 & $0.64-2.82$ \\
\hline Mood disorders (F3) & 36 & 1.55 & $1.12-2.15$ & 1.20 & $0.86-1.66$ \\
\hline Neurotic disorders (F4) & 12 & 1.20 & $0.68-2.11$ & 0.92 & $0.52-1.61$ \\
\hline Eating disorders (F50) & $<5$ & - & - & - & - \\
\hline Personality disorders (F60) & $<5$ & - & - & - & - \\
\hline Intellectual disorders (F7) & $<5$ & - & - & - & - \\
\hline Developmental disorders (F84) & $<5$ & - & - & - & - \\
\hline Behavioral disorders (F9) & $<5$ & - & - & - & - \\
\hline \multicolumn{6}{|c|}{ Psychiatric disorders and subsequent $\mathrm{BP}^{\mathrm{b}}$} \\
\hline & BP diagnosis $(\mathrm{N})$ & HR of BP & $\mathrm{Cl}$ & $\mathrm{HR}$ of $\mathrm{BP}{ }^{d}$ & $\mathrm{Cl}$ \\
\hline Any psychiatric disorder & 400 & 1.79 & $1.61-1.99$ & 1.40 & $1.25-1.56$ \\
\hline Organic disorders (F0) & 167 & 1.92 & $1.64-2.25$ & 1.55 & $1.32-1.81$ \\
\hline Substance use disorders (F1) & 79 & 2.32 & $1.86-2.91$ & 1.70 & $1.35-2.13$ \\
\hline Schizophrenia (F2) & 61 & 2.01 & $1.56-2.59$ & 1.57 & $1.21-2.02$ \\
\hline Mood disorders (F3) & 146 & 1.49 & $1.26-1.76$ & 1.13 & $0.95-1.34$ \\
\hline Neurotic disorders (F4) & 106 & 1.85 & $1.52-2.25$ & 1.41 & $1.16-1.71$ \\
\hline Eating disorders (F50) & $<5$ & - & - & - & - \\
\hline Personality disorders (F60) & 79 & 2.01 & $1.61-2.52$ & 1.53 & $1.22-1.92$ \\
\hline Intellectual disorders (F7) & 10 & 4.18 & $2.25-7.78$ & 2.96 & $1.58-5.51$ \\
\hline Developmental disorders (F84) & $<5$ & - & - & - & - \\
\hline Behavioral disorders (F9) & $<5$ & - & - & - & - \\
\hline
\end{tabular}

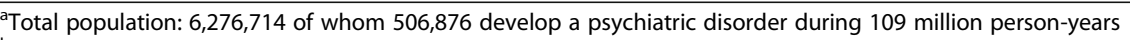

${ }^{\mathrm{b}}$ Total population: 6,448,090 of whom 2892 develop $\mathrm{BP}$, during 115 million person-years

'Adjusted for BP medications and diuretics

${ }^{\mathrm{d}}$ Adjusted for psychiatric medications and diuretics

with the exception of the association with mood disorders (Table 2, Fig. 1).

\section{The association between $A B D$ and psychiatric disorders}

Individuals diagnosed with $\mathrm{ABD}(N=5580)$ had elevated risk of developing any psychiatric disorder (HR 1.30, CI 1.15-1.48), organic disorder (HR 1.24, CI 1.05-1.46), mood (HR 1.49, CI 1.19-1.85), and neurotic disorder (HR 1.49 , CI 1.15-1.94), with a mean latency of 10.1 years.

When controlling for BP/ABD medications and diuretics, the association became non-significant, except for any psychiatric disorder. Among individuals with psychiatric disorders, the risk for subsequent $\mathrm{ABD}$ (mean latency of 15.4 years) was significantly higher for almost all psychiatric disorders in analysis, and independent of psychiatric medications and diuretics, with the exception of the association with mood disorders (Table 3, Fig. 2).

\section{Discussion}

In this large comprehensive national register study, several psychiatric disorders were significantly associated with BP in specific, as well as with the broad category of $\mathrm{ABD}$. Although the temporal patterns indicate bidirectionality, the risk of a psychiatric disorder preceding $\mathrm{BP}$ or ABD was greatest.

Our results extend the study by Försti et al. who reported an association between BP and schizophrenia, personality disorders, neurotic, and organic disorders [27]. In our study, mood disorders carried increased risk for BP (HR 1.49, CI 1.26-1.76), confirming all previous studies [11, 27, 28] except Teixeira and colleagues [30], whose small sample size and retrospective evaluation of depression may have precluded detection of significant associations.

We present a novel finding of prior intellectual disorders and substance use disorders exhibiting the highest 


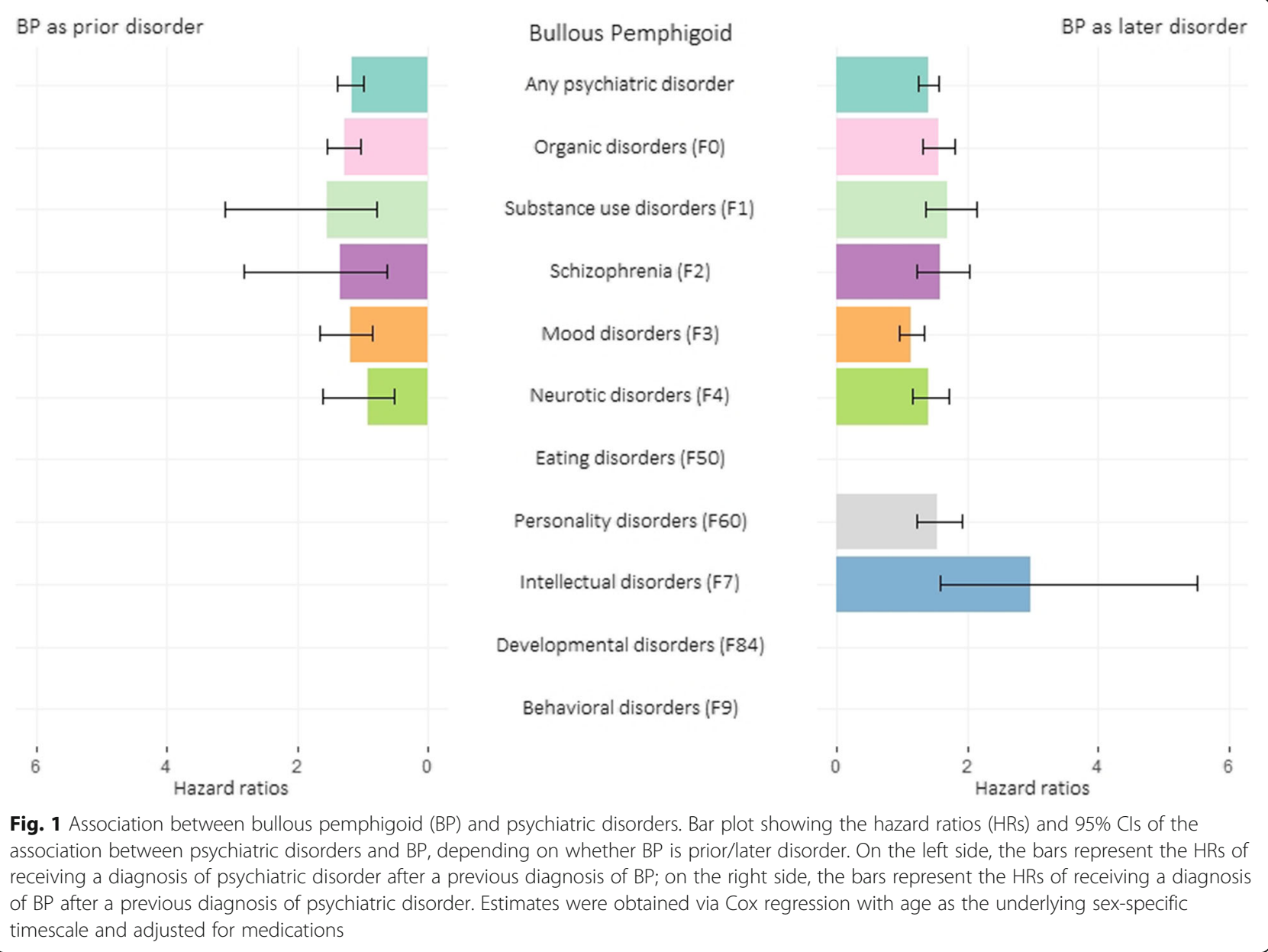

risk of BP of all psychiatric disorders (respectively 4-foldand 2-fold increased risk). However, for some other psychiatric disorders (e.g., eating disorders, developmental, and behavioral disorders), the overall number of cases was too few to perform the analysis or detect significant effects.

Organic disorders (e.g., demonstrable cerebral disease or brain injury) were the only psychiatric diagnosis that was significantly bidirectionally associated with BP, even after controlling for medications. According to a recent systematic review and meta-analysis [24] most studies provided evidence for neurological events preceding the development of BP [26, 30, 44, 45], but others reported high risk for some neurological disorders [46-48] in patients with a prior diagnosis of BP, during follow-up. Additional prospective cohort studies are required to clarify the temporal relation between $\mathrm{BP}$ and neurologic disorders. According to the current theory, the exposure of the BPAG1 neuronal antigen, following neurological damage or neuroinflammation, could trigger the production of autoantibodies that could cross-react with the epithelial BPAG1 isoform. Nevertheless, a similar pathophysiological mechanism could be hypothesized, given evidence of the involvement of immune activation in several of the psychiatric disorders associated with BP, such as schizophrenia [49], mood disorders [50], personality disorders [51], and substance use disorders [52].

Our work extends the literature by considering the role of both BP-related and psychiatric medications in increasing risk for the other class of illness. More than 50 medications have been identified to be associated with BP, with several explanatory theories proposed [53]. Drug-induced BP, a variant of idiopathic BP, can be clinically indistinguishable, and should be considered in older patients undergoing medication changes, as its course may be self-limiting when the medication is withdrawn. Although various diuretics are widely recognized to affect $\mathrm{BP}$ onset $[29,54-56]$, the association with psychiatric medications is less clear, in part due to methodological inconsistencies across studies. A register-based study examined the intake of psychiatric medications during the 2 years prior the diagnosis of $\mathrm{BP}$ and demonstrated that 
Table 3 Results for all bullous disorders (ABD) and psychiatric disorders

\begin{tabular}{|c|c|c|c|c|c|}
\hline \multicolumn{6}{|c|}{$A B D$ and subsequent psychiatric disorders ${ }^{a}$} \\
\hline & Psychiatric diagnosis (N) & HR of psychiatric diagnosis & $\mathrm{Cl}$ & HR of psychiatric diagnosis ${ }^{c}$ & $\mathrm{Cl}$ \\
\hline Any psychiatric disorder & 236 & 1.30 & $1.15-1.48$ & 1.17 & $1.03-1.33$ \\
\hline Organic disorders (F0) & 143 & 1.24 & $1.05-1.46$ & 1.18 & $1.00-1.39$ \\
\hline Substance use disorders (F1) & 17 & 1.16 & $0.72-1.87$ & 1.02 & $0.64-1.65$ \\
\hline Schizophrenia (F2) & 15 & 1.24 & $0.75-2.06$ & 1.21 & $0.73-2.01$ \\
\hline Mood disorders (F3) & 79 & 1.49 & $1.19-1.85$ & 1.24 & $1.00-1.55$ \\
\hline Neurotic disorders (F4) & 56 & 1.49 & $1.15-1.94$ & 1.29 & $0.99-1.67$ \\
\hline Eating disorders (F50) & $<5$ & - & - & - & - \\
\hline Personality disorders (F60) & 14 & 1.54 & $0.91-2.60$ & 1.38 & $0.81-2.32$ \\
\hline Intellectual disorders (F7) & 5 & 1.47 & $0.61-3.54$ & 1.43 & $0.60-3.45$ \\
\hline Developmental disorders (F84) & 5 & 1.01 & $0.42-2.43$ & 1.01 & $0.42-2.45$ \\
\hline Behavioral disorders (F9) & $<5$ & - & - & - & - \\
\hline \multicolumn{6}{|c|}{ Psychiatric disorders and subsequent $\mathrm{BP}^{\mathrm{b}}$} \\
\hline & ABD diagnosis $(\mathrm{N})$ & $\mathrm{HR}$ of $\mathrm{ABD}$ & $\mathrm{Cl}$ & $H R$ of $A B D^{d}$ & $\mathrm{Cl}$ \\
\hline Any psychiatric disorder & 694 & 1.72 & $1.58-1.86$ & 1.33 & $1.23-1.45$ \\
\hline Organic disorders (F0) & 226 & 1.80 & $1.57-2.06$ & 1.44 & $1.26-1.65$ \\
\hline Substance use disorders (F1) & 154 & 2.07 & $1.76-2.43$ & 1.50 & $1.27-1.77$ \\
\hline Schizophrenia (F2) & 104 & 1.77 & $1.45-2.15$ & 1.35 & $1.11-1.64$ \\
\hline Mood disorders (F3) & 251 & 1.49 & $1.31-1.69$ & 1.12 & $0.99-1.28$ \\
\hline Neurotic disorders (F4) & 216 & 1.77 & $1.54-2.03$ & 1.34 & $1.16-1.54$ \\
\hline Eating disorders (F50) & 6 & 1.49 & $0.66-3.33$ & 1.15 & $0.51-2.58$ \\
\hline Personality disorders (F60) & 156 & 1.90 & $1.62-2.23$ & 1.43 & $1.22-1.68$ \\
\hline Intellectual disorders (F7) & 16 & 2.52 & $1.54-4.12$ & 1.80 & $1.10-2.95$ \\
\hline Developmental disorders (F84) & - & - & - & - & - \\
\hline Behavioral disorders (F9) & - & - & - & - & - \\
\hline
\end{tabular}

aTotal population: 6,275,885 of whom 506,958 develop a psychiatric disorder during 110 million person-years

${ }^{\mathrm{b}}$ Total population: 6,446,852 of whom 5580 develop $A B D$, during 116 million person-years

'Adjusted for ABD medications and diuretics

${ }^{\mathrm{d}}$ Adjusted for psychiatric medications and diuretics

antipsychotics, antidepressants, and anxiolytics were significantly associated with BP [36]. These results agree with several previous findings [29, 33, 34, 57], but are in contrast with the study of Lloyd-Lavery et al. that stated that neither antipsychotics, antidepressants, nor anxiolytics were associated with BP [54]. Our findings show that psychiatric medications did not influence the risk of a subsequent BP diagnosis. Similarly, Bastuji-Garin and colleagues [29] considered medication intake as a potential confounding factor between mood disorders and $\mathrm{BP}$, however, they restricted the multivariate analysis to psycholeptic medications, whereas we considered the whole class of psychiatric medications. It is possible that any effect on $\mathrm{BP} / \mathrm{ABD}$ risk may not be equally distributed across psychoactive medications. Notwithstanding the majority of evidence supports the strong association between psychiatric medications and BP, we hypothesize that, even assuming the potential effect of medications, the association with psychiatric disorders is not only mediated by psychiatric medications.

By contrast, the medications prescribed for the treatment of BP/ABD accounted for the majority of risk of later psychiatric disorders. Systemic steroids are the first line treatment for $\mathrm{BP} / \mathrm{ABD}$ [58] and general consensus exists regarding their ability to induce the onset or reexacerbation of psychiatric symptoms and disorders [59, 60]. Psychiatric adverse effects typically consist of mild to moderate symptoms of anxiety, mood liability, and sleep disturbances that occur within the first week of treatment, are short-lasting, and reverse with the medication cessation [60]. However, serious conditions as delirium [61], psychosis $[62,63]$ and mood disorders [64-66] can occur, especially with high corticosteroid doses [59, 67].

Although the relation between corticosteroids and depression is well-documented, it is noteworthy that latelife depression can often result from multi-morbidity of 


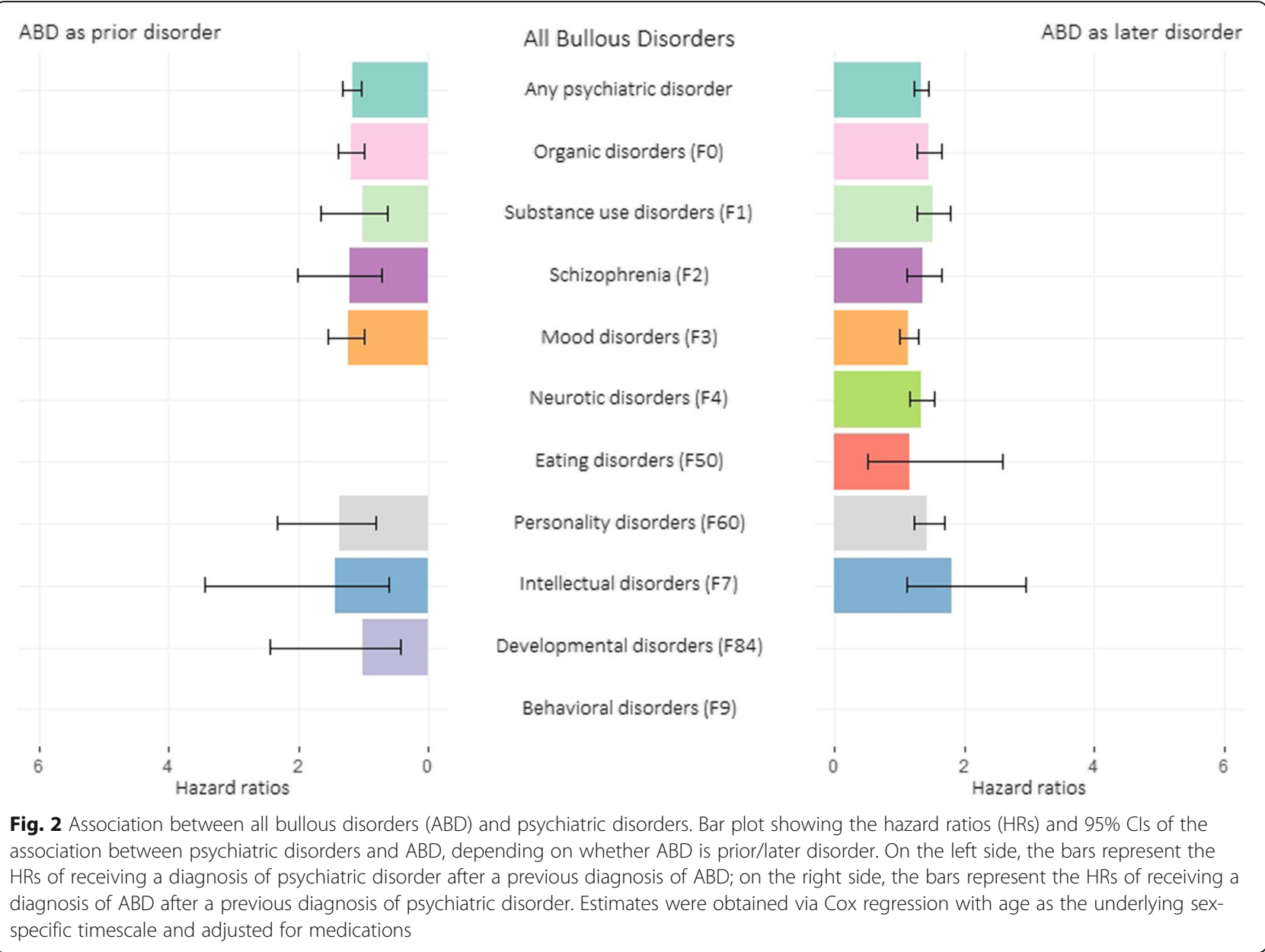

somatic illnesses and polypharmacy [68, 69]. However, for cases that are plausibly related to corticosteroids, there is evidence for a dose-dependent effect and lower corticosteroid doses and cautious dosage reduction are recommended [70, 71].

To the best of our knowledge, this is the first study to explore psychiatric comorbidity in the whole class of $\mathrm{ABD}$. The risk of a later $\mathrm{BP}$ or $\mathrm{ABD}$ was comparable for any psychiatric disorder. In contrast, the risk of developing a later psychiatric disorder after $A B D$ was higher than BP.

Our study has strengths and limitations. First, the large sample size provided sufficient power for most comparisons of these relatively rare dermatologic diseases. Second, by using the Danish national registers, we likely captured the majority of incident cases during the observation period as the bullous disorders are sufficiently distressing to warrant detection, especially in a national healthcare system where treatment is essentially free and universally available. These strengths support the validity and generalizability of the results. However, some limitations have to be addressed. Firstly, the use of registry data did not allow to directly verify either the dermatologic or psychiatric diagnoses. Nonetheless, the Danish registries have undergone considerable validation and showed to be reliable for epidemiological research, with good internal validity and accuracy $[39,72,73]$. Furthermore, only data about BP and psychiatric disorders treated in secondary care (hospital inpatients and outpatients) were collected, with a plausible selection bias of more severe cases. We were underpowered to explore the association of less common psychiatric disorders with BP/ABD. Lastly, since we examined the combined effect of medications, we are not able to draw specific conclusions about the specific effect of individual medications.

In conclusion, the risk of developing BP after having a psychiatric disorder is elevated and is independent of psychiatric medications. Conversely, the association between prior BP and later psychiatric disorders seem to be primarily attributable to the use of medications for the treatment of BP. Clinically, an integrated approach attending to both dermatological and psychiatric symptoms is recommended. Dermatologists treating $\mathrm{BP} / \mathrm{ABD}$ should remain vigilant and instruct patients under treatment about the possible development of both early and late psychiatric symptoms $[59,60]$, and refer them for 
psychiatric evaluation, when the medication cannot be reduced or discontinued $[60,74]$.

\section{Conclusions}

Early detection, together with the modification of pharmacotherapeutic approaches to BP, could lower risk of developing subsequent psychiatric disorders. Future science should include even larger and more comprehensive prospective studies to confirm the temporal relation and the pathogenic mechanisms that underlie the association between psychiatric disorders and BP.

\section{Abbreviations}

BP: Bullous pemphigoid; ABD: All bullous disorders; BP Ag1: Bullous pemphigoid antigen 1; BP Ag2: Bullous pemphigoid antigen 2; OR: Odds ratio; ICD: International Statistical Classification of Diseases and Related Health Problems; ATC: Anatomical Therapeutic Chemical; HR: Hazard ratio; $\mathrm{Cl}$ : Confidence interval

\section{Acknowledgements}

Not applicable.

\section{Authors' contributions}

LVP had full access to all the data in the study, analyzed the data, and takes responsibility for the integrity of the data and the accuracy of the data analysis. MR and LVP had full access to the results, and take responsibility for the accuracy of the data analysis. MR, LVP, MEB, ZL, LD, and CMB were involved with the concept and design of the study. MR, LVP, MEB, CMB interpreted the data analysis. MR, LVP, MEB, and CMB drafted the manuscript. $M R, L V P, M E B, Z L, L D$, and CMB provided critical revision of the manuscript. $M R$, LVP, MEB, and CMB provided additional administrative, technical, or material support. All authors have read and approved the final manuscript.

\section{Funding}

Dr. Rania is supported by Magna Graecia University Foundation (2019-256). Dr. Petersen is supported by grant R155-2014-1724 from the Lundbeck Foundation Initiative for Integrative Psychiatric Research (iPSYCH). Dr. Benros is supported by grants from The Independent Research Fund Denmark (grant 7025-00078B) and The Lundbeck Foundation (grant R268-2016-3925 and R278-2018-1411). Dr. Liu is an investigator supported in part by R01 AR070276, R01 AR072694, 19-2507, and the Department of Dermatology, University of North Carolina at Chapel Hill. Dr. Diaz is an investigator supported in part by RO1 AR32599 and CTSA-UL1TR002489 (LAD) and the Department of Dermatology, University of North Carolina School of Medicine. Dr. Bulik is supported by the Swedish Research Council (Vetenskapsrådet, award: 5382013-8864).

The sponsors had no role in the design and conduct of the study; collection, management, analysis, and interpretation of the data; preparation, review, or approval of the manuscript; and decision to submit the manuscript for publication. Open access funding provided by Karolinska Institute.

\section{Availability of data and materials}

Access to individual-level Denmark data is governed by Danish authorities. Each scientific project must be approved before initiation, and approval is granted to a specific Danish research institution. Researchers at Danish research institutions may obtain the relevant approvals and data access. International researchers may gain data access if governed by a Danish research institution having the needed approvals and data access.

\section{Ethics approval and consent to participate}

The use of data from the registers was approved by the Danish Data Protection Agency, the Danish National Board of Health and Statistics Denmark. According to Danish law, approval by the Ethics Committee and written informed consent were not required for register-based projects.

\section{Consent for publication}

Not applicable.

\section{Competing interests}

CM Bulik is a grant recipient from and a Scientific Advisory Board member for Shire, consultant for Idorsia and received royalties from Pearson. The other authors have no potential conflicts of interest to report.

\section{Author details}

'Department of Health Sciences, University Magna Graecia of Catanzaro, Catanzaro, Italy. ${ }^{2}$ Center for Clinical Research and Treatment of Eating Disorders, Mater Domini University Hospital, Catanzaro, Italy. ${ }^{3}$ Department of Medical Epidemiology and Biostatistics, Karolinska Institutet, Stockholm, Sweden. ${ }^{4}$ National Centre for Register-based Research, Aarhus BSS, Aarhus University, Aarhus, Denmark. ${ }^{5}$ Centre for Integrated Register-based Research (CIRRAU), Aarhus University, Aarhus, Denmark. ${ }^{6}$ Copenhagen Research Centre for Mental Health, Mental Health Centre Copenhagen, Copenhagen University Hospital, Copenhagen, Denmark. 'Departments of Dermatology, Microbiology and Immunology, University of North Carolina at Chapel Hill, Chapel Hill, NC, USA. ${ }^{8}$ Department of Psychiatry, University of North Carolina at Chapel Hill, Chapel Hill, NC, USA. ${ }^{9}$ Department of Nutrition, University of North Carolina at Chapel Hill, Chapel Hill, NC, USA.

Received: 20 May 2020 Accepted: 5 August 2020

Published online: 20 August 2020

\section{References}

1. Lever W. In: Charles C, Thomas P, editors. Pemphigus and pemphigoid. Springfield: Charles C Thomas, Publisher; 1965.

2. Culton DA, Liu Z, Diaz LA. Bullous Pemphigoid. In: Kang S, Amagai M, Bruckner AL, et al., editors. Fitzpatrick's dermatology. 9th ed. New York: McGraw-Hill Education; 2019.

3. Bertram F, Brocker EB, Zillikens D, et al. Prospective analysis of the incidence of autoimmune bullous disorders in Lower Franconia, Germany. J Dtsch Dermatol Ges. 2009;7:434-40. https://doi.org/10.1111/j. 1610-0387.2008.06976.x.

4. Brick KE, Weaver $\mathrm{CH}$, Lohse CM, et al. Incidence of bullous pemphigoid and mortality of patients with bullous pemphigoid in Olmsted County, Minnesota, 1960 through 2009. J Am Acad Dermatol. 2014;71:92-9. https://doi.org/10.1016/j.jaad.2014.02.030.

5. Försti AK, Jokelainen J, Timonen $M$, et al. Increasing incidence of bullous pemphigoid in northern Finland: a retrospective database study in Oulu University hospital. Br J Dermatol. 2014;171:1223-6.

6. Gudi VS, White MI, Cruickshank N, et al. Annual incidence and mortality of bullous pemphigoid in the Grampian Region of North-east Scotland. $\mathrm{Br} J$ Dermatol. 2005;153:424-7. https://doi.org/10.1111/j.1365-2133.2005.06662.x.

7. Marazza G, Pham HC, Scharer L, et al. Incidence of bullous pemphigoid and pemphigus in Switzerland: A 2-year prospective study. Br J Dermatol. 2009; 161:861-8. https://doi.org/10.1111/j.1365-2133.2009.09300.x.

8. Thorslund K, Seifert O, Nilzén K, et al. Incidence of bullous pemphigoid in Sweden 2005-2012: a nationwide population-based cohort study of 3761 patients. Arch Dermatol Res. 2017;309:721-7.

9. Langan SM, Smeeth L, Hubbard R, et al. Bullous pemphigoid and pemphigus vulgaris-incidence and mortality in the UK: Population based cohort study. Bmj. 2008;337:a180. https://doi.org/10.1136/bmj.a180.

10. Schmidt E, Zillikens D. Pemphigoid diseases. Lancet. 2013;381:320-32. https://doi.org/10.1016/s0140-6736(12)61140-4.

11. Kouris A, Platsidaki E, Christodoulou C, et al. Quality of life, depression, anxiety and loneliness in patients with bullous pemphigoid. A case control study. An Bras Dermatol. 2016:91:601-3. https://doi.org/10.1590/abd18064841.20164935.

12. Wang EQ, Radjenovic M, Castrillon MA, et al. The effect of autoimmune blistering diseases on work productivity. J Eur Acad Dermatol Venereol. 2018;32:1959-66. https://doi.org/10.1111/jdv.15062.

13. Kridin K, Shihade W, Bergman R. Mortality in patients with bullous pemphigoid A retrospective cohort study, systematic review and meta-analysis. Acta Derm Venereol. 2019;99:72-7. https://doi.org/10.2340/00015555-2930.

14. Stanley JR, Hawley-Nelson P, Yuspa SH, et al. Characterization of bullous pemphigoid antigen: A unique basement membrane protein of stratified squamous epithelia. Cell. 1981; 24: 897-903. DOl: https://doi.org/https://doi. org/10.1016/0092-8674(81)90115-X.

15. Giudice GJ, Emery DJ, Diaz LA. Cloning and primary structural analysis of the bullous pemphigoid autoantigen BP180. J Invest Dermatol. 1992;99:24350. https://doi.org/10.1111/1523-1747.ep12616580. 
16. Liu Z, Diaz LA, Troy JL, et al. A passive transfer model of the organ-specific autoimmune disease, bullous pemphigoid, using antibodies generated against the hemidesmosomal antigen, BP180. J Clin Invest. 1993;92:2480-8. https://doi.org/10.1172/JCl116856.

17. Lin L, Hwang BJ, Culton DA, et al. Eosinophils mediate tissue injury in the autoimmune skin disease bullous pemphigoid. J Invest Dermatol. 2018;138: 1032-43. https://doi.org/10.1016/j.jid.2017.11.031.

18. Seppänen $\mathrm{AO}$. Both bullous pemphigoid antigens are expressed in the central nervous system. Br J Dermatol. 2012;166:683-4. https://doi.org/10. 1111/j.1365-2133.2011.10641.x.

19. Seppanen A, Suuronen T, Hofmann SC, et al. Distribution of collagen XVII in the human brain. Brain Res. 2007;1158:50-6. https://doi.org/10.1016/j. brainres.2007.04.073.

20. Foureur N, Mignot S, Senet $P$, et al. Correlation between the presence of type-2 anti-pemphigoid antibodies and dementia in elderly subjects with no clinical signs of pemphigoid. Ann Dermatol Venereol. 2006;133:439-43.

21. Laffitte $E$, Burkhard $P R$, Fontao $L$, et al. Bullous pemphigoid antigen 1 isoforms: Potential new target autoantigens in multiple sclerosis? $\mathrm{Br} J$ Dermatol. 2005;152:537-40. https://doi.org/10.1111/j.1365-2133.2004.06338.x

22. Chen J, Li L, Chen J, et al. Sera of elderly bullous pemphigoid patients with associated neurological diseases recognize bullous pemphigoid antigens in the human brain. Gerontology. 2011;57:211-6. https://doi.org/10.1159/ 000315393.

23. Milani-Nejad N, Zhang M, Kaffenberger J. The association between bullous pemphigoid and neurological disorders: A systematic review. Eur J Dermatol. 2017;27:472-81. https://doi.org/10.1684/ejd.2017.3066.

24. Lai YC, Yew YW, Lambert WC. Bullous pemphigoid and its association with neurological diseases: A systematic review and meta-analysis. J Eur Acad Dermatol Venereol. 2016;30:2007-15. https://doi.org/10.1111/jdv.13660.

25. Li L, Chen J, Wang B, et al. Sera from patients with bullous pemphigoid (BP) associated with neurological diseases recognized BP antigen 1 in the skin and brain. Br J Dermatol. 2009;160:1343-5. https://doi.org/10.1111/j.13652133.2009.09122.X.

26. Chen YJ, Wu CY, Lin MW, et al. Comorbidity profiles among patients with bullous pemphigoid: a nationwide population-based study. Br J Dermatol. 2011;165:593-9. https://doi.org/10.1111/j.1365-2133.2011.10386.x.

27. Försti A-K, Jokelainen J, Ansakorpi $H$, et al. Psychiatric and neurological disorders are associated with bullous pemphigoid - a nationwide Finnish Care Register study. Sci Rep. 2016;6:37125. https://doi.org/10.1038/srep37125.

28. Ren Z, Hsu D, Brieva J, et al. Hospitalization, inpatient burden and comorbidities associated with bullous pemphigoid in the USA. Br J Dermatol. 2017;176:87-99.

29. Bastuji-Garin S, Joly P, Lemordant $P$, et al. Risk factors for bullous pemphigoid in the elderly: a prospective case-control study. J Invest Dermatol. 2011;131:637-43.

30. Teixeira VB, Cabral R, Brites MM, et al. Bullous pemphigoid and comorbidities: a case-control study in Portuguese patients. An Bras Dermatol. 2014;89:274-8

31. Bhangle SD, Kramer N, Rosenstein ED. Corticosteroid-induced neuropsychiatric disorders: review and contrast with neuropsychiatric lupus. Rheumatol Int. 2013;33:1923-32. https://doi.org/10.1007/s00296-013-2750-z.

32. Gable M, Depry D. Sustained corticosteroid- induced mania and psychosis despite cessation: A case study and brief literature review. Int J Psychiatry Med. 2015;50:398-404. https://doi.org/10.1177/0091217415612735.

33. Caccavale S, Mea EE, La Montagna M. Bullous pemphigoid induced by escitalopram in a patient with depression. G Ital Dermatol Venereol. 2016; 151:122-3.

34. Rault S, Grosieux-Dauger C, Verraes $S$, et al. Bullous pemphigoid induced by fluoxetine. Br J Dermatol. 1999;141:755-6. https://doi.org/10.1046/j.13652133.1999.03130.x.

35. Tan CW, Pang Y, Sim B, et al. The association between drugs and bullous pemphigoid. Br J Dermatol. 2017;176:549-51. https://doi.org/10.1111/bjd.15195.

36. Varpuluoma O, Jokelainen J, Forsti AK, et al. Drugs used for neurologic and psychiatric conditions increase the risk for bullous pemphigoid: A casecontrol study. J Am Acad Dermatol. 2019;81:250-3. https://doi.org/10.1016/j. jaad.2019.02.017.

37. Pedersen CB. The Danish Civil Registration System. Scand J Public Health. 2011;39:22-5. https://doi.org/10.1177/1403494810387965.

38. Lynge E, Sandegaard JL, Rebolj M. The Danish National Patient Register. Scand J Public Health. 2011;39:30-3. https://doi.org/10.1177/ 1403494811401482.
39. Mors O, Perto GP, Mortensen PB. The Danish Psychiatric Central Research Register. Scand J Public Health. 2011;39:54-7. https://doi.org/10.1177/ 1403494810395825.

40. Ripoll OP, Pedersen C, Agerbo E, et al. O5.3. A comprehensive nationwide study of comorbidity within treated mental disorders-a Danish registerbased study. Schizophr Bull. 2018;44:S87.

41. Kildemoes HW, Sorensen HT, Hallas J. The Danish National Prescription Registry. Scand J Public Health. 2011;39:38-41. https://doi.org/10.1177/ 1403494810394717

42. WHO Collaborating Centre for Drug Statistics Methodology. Guidelines for ATC classification and DDD assignment, 2019, https://www.whocc.no/filearchive/ publications/2020_guidelines_web.pdf.

43. StataCorp. Stata Statistical Software: Release 15. College Station: StataCorp LP; 2017.

44. Langer-Gould A, Albers KB, Van Den Eeden SK, et al. Autoimmune diseases prior to the diagnosis of multiple sclerosis: a population-based case-control study. Mult Scler. 2010;16:855-61. https://doi.org/10.1177/1352458510369146.

45. Langan SM, Groves RW, West J. The relationship between neurological disease and bullous pemphigoid: A population-based case-control study. Invest Dermatol. 2011;131:631-6. https://doi.org/10.1038/jid.2010.357.

46. Brick KE, Weaver $\mathrm{CH}$, Savica $\mathrm{R}$, et al. A population-based study of the association between bullous pemphigoid and neurologic disorders. J Am Acad Dermatol. 2014;71:1191-7. https://doi.org/10.1016/j.jaad.2014.07.052.

47. Kibsgaard L, Rasmussen M, Lamberg A, et al. Increased frequency of multiple sclerosis among patients with bullous pemphigoid: a populationbased cohort study on comorbidities anchored around the diagnosis of bullous pemphigoid. Br J Dermatol. 2017;176:1486-91.

48. Yang $\mathrm{YW}$, Chen $\mathrm{YH}$, Xirasagar $\mathrm{S}$, et al. Increased risk of stroke in patients with bullous pemphigoid: A population-based follow-up study. Stroke. 2011; 42:319-23. https://doi.org/10.1161/strokeaha.110.596361.

49. Buckley PF. Neuroinflammation and schizophrenia. Curr Psychiatry Rep. 2019;21:72. https://doi.org/10.1007/s11920-019-1050-z.

50. Pinto JV, Passos IC, Librenza-Garcia D, et al. Neuron-glia interaction as a possible pathophysiological mechanism of bipolar disorder. Curr Neuropharmacol. 2018;16:519-32. https://doi.org/10.2174/ $1570159 \times 15666170828170921$.

51. Fanning JR, Lee R, Gozal D, et al. Childhood trauma and parental style: Relationship with markers of inflammation, oxidative stress, and aggression in healthy and personality disordered subjects. Biol Psychol. 2015;112:56-65. https://doi.org/10.1016/j.biopsycho.2015.09.003.

52. Clark KH, Wiley CA, Bradberry CW. Psychostimulant abuse and neuroinflammation: Emerging evidence of their interconnection. Neurotox Res. 2013;23:174-88. https://doi.org/10.1007/s12640-012-9334-7.

53. Stavropoulos PG, Soura E, Antoniou C. Drug-induced pemphigoid: A review of the literature. J Eur Acad Dermatol Venereol. 2014;28:1133-40. https://doi. org/10.1111/jdv.12366

54. Lloyd-Lavery A, Chi C-C, Wojnarowska F, et al. The associations between bullous pemphigoid and drug use: a UK case-control study. JAMA Dermatol. 2013;149:58-62. https://doi.org/10.1001/2013.jamadermatol.376.

55. Lee JJ, Downham TF 2nd. Furosemide-induced bullous pemphigoid: Case report and review of literature. J Drugs Dermatol. 2006:5:562-4.

56. Modeste $A B$, Cordel N, Courville $P$, et al. Bullous pemphigoid induced by spironolactone. Ann Dermatol Venereol. 2002;129:56-8.

57. Wijeratne C, Webster P. Risperidone and bullous pemphigoid. Am J Psychiatry. 1996;153:735. https://doi.org/10.1176/ajp.153.5.735a.

58. Feliciani $C$, Joly $\mathrm{P}$, Jonkman MF, et al. Management of bullous pemphigoid: The European Dermatology Forum consensus in collaboration with the European Academy of Dermatology and Venereology. Br J Dermatol. 2015; 172:867-77. https://doi.org/10.1111/bjd.13717.

59. Kusljic S, Manias E, Gogos A. Corticosteroid-induced psychiatric disturbances: It is time for pharmacists to take notice. Res Soc Adm Pharm. 2016;12:355-60. https://doi.org/10.1016/j.sapharm.2015.05.012.

60. Kenna HA, Poon AW, de los Angeles CP, et al. Psychiatric complications of treatment with corticosteroids: Review with case report. Psychiatry Clin Neurosci. 2011;65:549-60. https://doi.org/10.1111/j.1440-1819.2011.02260.x.

61. Stoudemire A, Anfinson T, Edwards J. Corticosteroid-induced delirium and dependency. Gen Hosp Psychiatry. 1996;18:196-202. https://doi.org/10.1016/ 0163-8343(96)00005-9.

62. Appenzeller S, Cendes F, Costallat LT. Acute psychosis in systemic lupus erythematosus. Rheumatol Int. 2008:28:237-43. https://doi.org/10.1007/ s00296-007-0410-x. 
63. Mullen RS, Romans-Clarkson SE. Behavioural sensitisation and steroid-induced psychosis. Br J Psychiatry. 1993;162:549-51. https://doi.org/10.1192/bjp.162.4.549.

64. Wada K, Yamada N, Suzuki H, et al. Recurrent cases of corticosteroidinduced mood disorder: Clinical characteristics and treatment. J Clin Psychiatry. 2000;61:261-7. https://doi.org/10.4088/jcp.v61n0404.

65. Bolanos SH, Khan DA, Hanczyc M, et al. Assessment of mood states in patients receiving long-term corticosteroid therapy and in controls with patient-rated and clinician-rated scales. Ann Allergy Asthma Immunol. 2004; 92:500-5. https://doi.org/10.1016/s1081-1206(10)61756-5.

66. Brown ES, Chandler PA. Mood and cognitive changes during systemic corticosteroid therapy. Prim Care Companion J Clin Psychiatry. 2001;3:17-21. https://doi.org/10.4088/pcc.v03n0104.

67. Lewis DA, Smith RE. Steroid-induced psychiatric syndromes. A report of 14 cases and a review of the literature. J Affect Disord. 1983;5:319-32. https://doi.org/10.1016/0165-0327(83)90022-8.

68. Aziz R, Steffens DC. What are the causes of late-life depression? Psychiatr Clin North Am. 2013;36:497-516. https://doi.org/10.1016/.jpsc.2013.08.001.

69. Holvast $F$, van Hattem BA, Sinnige J, et al. Late-life depression and the association with multimorbidity and polypharmacy: A cross-sectional study. Fam Pract. 2017;34:539-45. https://doi.org/10.1093/fampra/cm×018.

70. Richter B, Neises G, Clar C. Glucocorticoid withdrawal schemes in chronic medical disorders. A systematic review. Endocrinol Metab Clin N Am. 2002 31:751-78. https://doi.org/10.1016/s0889-8529(02)00008-7.

71. Program TBCDS. The Boston Collaborative Drug Surveillance Program. Acute adverse reactions to prednisone in relation to dosage. Clin Pharmaco Ther. 1972;13:694-8. https://doi.org/10.1002/cpt1972135part1694

72. Kessing L. Validity of diagnoses and other clinical register data in patients with affective disorder. Eur Psychiatry. 1998;13:392-8. https://doi.org/10, 1016/s0924-9338(99)80685-3.

73. Jakobsen KD, Frederiksen JN, Hansen T, et al. Reliability of clinical ICD-10 schizophrenia diagnoses. Nord J Psychiatry. 2005;59:209-12. https://doi.org/ 10.1080/08039480510027698

74. Warrington TP, Bostwick JM. Psychiatric adverse effects of corticosteroids. Mayo Clin Proc. 2006;81:1361-7. https://doi.org/10.4065/81.10.1361.

\section{Publisher's Note}

Springer Nature remains neutral with regard to jurisdictional claims in published maps and institutional affiliations.

Ready to submit your research? Choose BMC and benefit from:

- fast, convenient online submission

- thorough peer review by experienced researchers in your field

- rapid publication on acceptance

- support for research data, including large and complex data types

- gold Open Access which fosters wider collaboration and increased citations

- maximum visibility for your research: over $100 \mathrm{M}$ website views per year

At $\mathrm{BMC}$, research is always in progress.

Learn more biomedcentral.com/submissions 